\title{
Biofortification of wheat grain with iron and zinc: integrating novel genomic resources and knowledge from model crops
}

\author{
Philippa Borrill ${ }^{1}$, James M. Connorton ${ }^{1}$, Janneke Balk ${ }^{1,2}$, Anthony J. Miller ${ }^{1}$, Dale Sanders ${ }^{1}$ and \\ Cristobal Uauy ${ }^{1,3}$ *
}

1 John Innes Centre, Norwich, UK

${ }^{2}$ School of Biological Sciences, University of East Anglia, Norwich, UK

${ }^{3}$ National Institute of Agricultural Botany, Cambridge, UK

\section{Edited by:}

Lorraine Elizabeth Williams, University

of Southampton, UK

Reviewed by:

Stephan Clemens, University of

Bayreuth, Germany

Dimah Habash, Securewheat

Consultancy, UK

${ }^{*}$ Correspondence:

Cristobal Uauy, John Innes Centre

Norwich Research Park, Norwich NR4

$7 \cup H, U K$

e-mail:cristobal.uauy@jic.ac.uk
Wheat, like many other staple cereals, contains low levels of the essential micronutrients iron and zinc. Up to two billion people worldwide suffer from iron and zinc deficiencies, particularly in regions with predominantly cereal-based diets. Although wheat flour is commonly fortified during processing, an attractive and more sustainable solution is biofortification, which requires developing new varieties of wheat with inherently higher iron and zinc content in their grains. Until now most studies aimed at increasing iron and zinc content in wheat grains have focused on discovering natural variation in progenitor or related species. However, recent developments in genomics and transformation have led to a step change in targeted research on wheat at a molecular level. We discuss promising approaches to improve iron and zinc content in wheat using knowledge gained in model grasses. We explore how the latest resources developed in wheat, including sequenced genomes and mutant populations, can be exploited for biofortification. We also highlight the key research and practical challenges that remain in improving iron and zinc content in wheat.

Keywords: nutritional enhancement, cereals, transgenic, genomics, model to crop

\section{INTRODUCTION}

All living organisms require essential mineral micronutrients to maintain metabolism and humans obtain these from their diet (Welch and Graham, 2004). However staple grains such as wheat often contain suboptimal quantities of micronutrients, especially iron $(\mathrm{Fe})$ and zinc $(\mathrm{Zn})$, and most of this content is removed by milling. In regions where the human diet consists mainly of cereals this leads to deficiencies in micronutrients. The World Health Organization estimates that approximately $25 \%$ of the world's population suffers from anemia (WHO, 2008), and that Fedeficiency anemia led to the loss of over 46,000 disability adjusted life years (DALYs) in 2010 alone (Murray and Lopez, 2013). An estimated $17.3 \%$ of people worldwide are at risk of inadequate $\mathrm{Zn}$ intake (Wessells and Brown, 2012) and Zn-deficiency leads to estimated annual deaths of 433,000 children under the age of five (WHO, 2009).

There are many possible strategies to improve micronutrient intake in the human diet including dietary diversification, mineral supplementation and post-harvest food fortification. However, these strategies depend on continued investment and infrastructure, and current levels of post-harvest fortification of $\mathrm{Fe}$ are often inadequate (White and Broadley, 2009; Gomez-Galera et al., 2010; Hurrell et al., 2010). Biofortification circumvents these problems by improving the micronutrient content of the crops themselves by increasing mineral levels and bioavailability in the edible parts. Improving crop varieties by either conventional breeding or transgenic methods has the advantage that once the initial research and development is completed, the benefits from these nutritionally-enhanced crops will be sustainable with little further investment (Gomez-Galera et al., 2010).

Many studies have shown that there is a wide variation in grain $\mathrm{Fe}$ and $\mathrm{Zn}$ concentrations in wild relatives of modern wheat and the concentrations found can significantly exceed those found in modern elite cultivars (Cakmak et al., 2000; Monasterio and Graham, 2000). This natural variation can be utilized to biofortify wheat for Fe and $\mathrm{Zn}$, such as has been achieved using the transcription factor NAM-B1 (Uauy et al., 2006) which was originally identified for increasing protein content in wild emmer (Triticum turgidum ssp dicoccoides). In near isogenic lines the presence of NAM-B1 increased Fe and $\mathrm{Zn}$ grain concentrations by 18 and $12 \%$, respectively, (Distelfeld et al., 2007). This gene is being widely used in breeding programes across several continents (Kumar etal., 2011; Randhawa et al., 2013; Tabbita et al., 2013).

Recent technological developments present new opportunities that can complement natural variation and genome-wide association studies, and lead to faster improvements in $\mathrm{Fe}$ and $\mathrm{Zn}$ grain content. Therefore here we focus on how the dramatic increase in wheat genomic sequence availability combined with functional genomic approaches can be used to their fullest potential to engineer new varieties of wheat with improved $\mathrm{Fe}$ and $\mathrm{Zn}$ content. 


\section{ADVANCES IN WHEAT RESOURCES APPLICABLE TO IMPROVING FE AND ZN GRAIN CONTENT}

To date, molecular breeding in bread wheat has been hindered by its large genome size (16 Gb: five times that of humans), its polyploid nature (tetraploid pasta and hexaploid bread wheat), and the high nucleotide similarity between these genomes (>95\% similar in genes). However, recent advances in technology will greatly increase the rate of discovery and functional characterization of wheat genes, and provide the tools with which to deploy this knowledge into improved varieties. Some of these advances are outlined below.

\section{GENOME AND GENE SEQUENCE AVAILABILITY}

In the last 5 years the amount of publicly available wheat genomic sequence has massively expanded. The International Wheat Genome Sequencing Consortium has coordinated the purification of individual chromosome arms using flow sorting (Safar et al., 2004) followed by shotgun sequencing and assembly into contigs of an average size of $2.5 \mathrm{~kb}$. These genome-specific contigs have recently been released in EnsemblPlants allowing wheat researchers to separate and distinguish the homoeologous genomes for the first time. Physical maps of BAC libraries made from these purified chromosome arms are being constructed (Paux et al., 2008) to generate a high quality reference. A complementary strategy, whole genome shotgun (WGS) sequencing, has been used to generate a $5 \mathrm{x}$ coverage of the wheat genome, using orthologous sequences from multiple grasses to guide assembly (Brenchley et al., 2012). Draft sequences for the A and D genome progenitors, T. urartu (Ling et al., 2013) and Aegilops tauschii (Jia et al., 2013), were also created using a WGS approach followed by de novo assembly. Combining the WGS sequencing with the physical map strategy is leading to an unprecedented wealth of genomic information and will ultimately lead to a reliable reference sequence for polyploid wheat.

In parallel, the ability to access genic sequence through RNAseq and exome capture (Saintenac et al., 2011; Trick et al., 2012; Winfield etal., 2012) is enabling the identification of single nucleotide polymorphisms and the development of publicly available genome-specific markers for genetic mapping in polyploid wheat (Wilkinson et al., 2012; Allen et al., 2013). Recently a comprehensive set of homoeolog-specific gene models for polyploid wheat has been published (Krasileva et al., 2013). In short, wheat researchers now have access to genome-specific contig assemblies (albeit partial and fragmented), draft reference genomes, gene models and large SNP datasets. Together, these tools should enable more precise mapping and deployment of grain Fe and $\mathrm{Zn}$ traits through marker assisted selection.

\section{NOVEL EXPERIMENTS USING SEQUENCE DATA RESOURCES}

The wealth of sequence data, together with the reduced cost of sequencing, allows new ways of investigating gene function related to grain Fe and Zn. For example, RNA-seq was applied to identify differentially expressed genes in lines with reduced expression of NAM genes (Cantu et al., 2011). Many classes of genes including transporters, hormone regulated genes and transcription factors were identified. This study generates leads for investigations into the early stages of senescence and nutrient remobilisation that relate directly to micronutrient content in wheat grains. The differentially expressed NAM-regulated genes can now be further pursued through the reverse genetic resources available in wheat (see below). The refinement of methods to analyze RNA-seq data (Duan et al., 2012) together with homoeolog-specific gene models will provide increased resolution to transcriptome studies as reads can be assigned more accurately to specific genomes (Krasileva et al., 2013).

\section{REVERSE GENETIC MUTANT RESOURCES}

The major advances and cost reduction in sequencing technology has also created the opportunity to characterize existing chemically mutagenised populations (Uauy et al., 2009; Sestili et al., 2010) for rapid discovery of mutants in specific genes. The newly developed gene models (Krasileva et al., 2013) are being combined with exome capture approaches to enrich for protein-coding genes in both tetraploid and hexaploid mutant populations. Over 3,000 individuals will be sequenced and mutations identified and organized for online access (Uauy and Dubcovsky, personal communication). Therefore in the very near future, researchers will be able to order mutants in their gene of interest through a simple in silico search as is standard in many model species. The availability of such resources will allow faster characterization of gene function in wheat and will provide valuable alleles for breeding.

\section{TRANSGENIC METHOD IMPROVEMENTS}

Producing transgenic wheat has previously been a major bottleneck in investigating gene function. The efficiency of wheat transformation still lags behind the efficiency of barley transformation but it is constantly improving and a wide range of promoters is available to target transgene expression to particular tissues or developmental stages (Harwood, 2012). In addition, high-throughput Agrobacterium-mediated transformation of wheat is now possible through a patented technology (PureIntro; WO 95/06722) from Japan Tobacco which has been licensed to several institutions and delivers transformation efficiencies above 30\%. However challenges still remain. These relate primarily to costs and the ability to produce genotypeindependent transformation protocols, since most reports utilize Bobwhite or Fielder which are not suitable for commercialisation of transgenic wheat (Li et al., 2012). The ability to transform any cultivar of wheat, at a reasonable price, would allow transformation into elite lines which would speed up breeding programes and also allow research to be carried out in a more appropriate background.

\section{TRANSFERRING MODEL CROP KNOWLEDGE INTO WHEAT THE PATHWAYS FROM THE ROOTS TO THE GRAIN AND THE IMPORTANCE OF BIOAVAILABILITY}

Much work has been carried out to understand the distinct routes $\mathrm{Fe}$ and $\mathrm{Zn}$ take to reach the grain in diploid crop species such as rice, maize, and barley. Conservation of these pathways between species allows predictions about Fe and $\mathrm{Zn}$ transport in wheat where less is known. Recent reviews have covered the pathways in model crops extensively (Palmgren et al., 2008; Curie et al., 2009; Conte and Walker, 2011; Waters and Sankaran, 2011; White and Broadley, 2011; Borg et al., 2012; Kobayashi and Nishizawa, 
2012; Lee etal., 2012; Sperotto et al., 2012; Schroeder et al., 2013) so here we will briefly outline the putative pathways in wheat and then discuss key steps to target for crop improvement (Figure 1).

The uptake of Fe and $\mathrm{Zn}$ from the soil occurs via two processes in plants: direct uptake of $\mathrm{Fe}^{2+}$ and $\mathrm{Zn}^{2+}$ by ZRT-, IRT-like proteins (ZIPs) or via secretion of phytosiderophores (PSs) which chelate Fe cations and are subsequent taken up by yellow stripe like (YSL) transporters (Sperotto et al., 2012). The chelation strategy is generally used for Fe uptake in monocots such as wheat. In many steps of $\mathrm{Fe}$ and $\mathrm{Zn}$ transport the same families of proteins are involved, however the two metals are treated separately by plants often by the involvement of different members of multigene families. Metal chelators such as nicotianamine (NA) are important for radial movement of Fe and $\mathrm{Zn}$ through the root (Rellán-Álvarez et al., 2010; Deinlein et al., 2012) and the transport of $\mathrm{Zn}$ into the vacuole affects overall $\mathrm{Zn}$ transport through the roots into the shoot (Morel et al., 2009; Haydon et al., 2012). Fe and $\mathrm{Zn}$ are loaded into the xylem where $\mathrm{Zn}$ can move as a cation or in a complex with organic acids such as citrate (Lu et al., 2013), and Fe is chelated by citrate (Rellán-Álvarez et al., 2010). Transfer from xylem to phloem can occur in the root or basal part of the shoot or during remobilisation from the leaves during grain filling and is facilitated by ZIP and YSL family proteins. In wheat all nutrients enter the grain from the phloem because the xylem is discontinuous (Zee and O'Brien, 1970). In the phloem Fe and Zn are transported as complexes with NA or small proteins. Transporters from the maternal tissue into the endosperm cavity and into the aleurone and embryo have been proposed; several are members of the ZIP, YSL, and metal tolerance protein (MTP) families (Borg et al., 2009; Tauris et al., 2009).

In wheat grain most Fe and $\mathrm{Zn}$ is located in the aleurone layer which is lost during milling. This problem is further compounded by the fact that Fe in these tissues is deposited mainly in protein storage vacuoles (PSVs; Regvar et al., 2011) where it is bound to phytate, which makes it poorly bioavailable to humans (Borg et al., 2009). Ferritin, which forms large Fe-rich nanoparticles, is generally regarded as a more bioavailable storage form and is present in the widely consumed endosperm amyloplasts (Balmer et al., 2006). Thus it is important to not only consider the total content of $\mathrm{Fe}$ and $\mathrm{Zn}$ in grain, but also the tissue localization and speciation (as chelates, protein particles or other), which affects their bioavailability.

Many of the steps described above have been modified by transgenic approaches in diploid crop species. We discuss below some promising studies and how this knowledge can be used to improve $\mathrm{Fe}$ and $\mathrm{Zn}$ grain content and bioavailability in wheat.

\section{TRANSGENIC APPROACHES IN RICE}

Several studies have over-expressed genes involved in the pathway for $\mathrm{Fe}$ and $\mathrm{Zn}$ transport in rice with promising results showing increased bioavailability of Fe and no negative impact on yield. Over-expression of NA synthase (NAS) led to 2-3 fold increases in $\mathrm{Fe}$ and $\mathrm{Zn}$ content in paddy grown grain and importantly feeding this grain to anemic mice led to the recovery of normal hemoglobin and haematocrit levels within 2 weeks, whereas wild-type grain did not (Lee et al., 2009). Multiplexing genes involved at several steps has enabled even larger increases in Fe content, although bioavailability was not tested. Expressing NAS, ferritin and phytase resulted in a 6-fold increase in Fe in polished rice grains (Wirth et al., 2009). The authors suggest that the combination of these three transgenes did not significantly affect overall Fe homeostasis, shown by expression analysis of 28 endogenous rice genes in Fe-deficient and sufficient conditions (Wang et al., 2013). This suggests that a mechanism combining both increased translocation (NAS) and expanded sink strength (ferritin) could be suitable to enhance rice (and wheat) endosperm Fe content.

\section{APPLYING TRANSGENIC APPROACHES TO WHEAT}

At present, studies in wheat are restricted to the endospermspecific expression of wheat or soybean ferritin which led to increases in grain iron content of 1.5 to 1.9 -fold and 1.1 to 1.6fold respectively (Borg et al., 2012; Sui et al., 2012) and increasing phytase activity (Holm et al., 2002). These studies give proof of concept that grain Fe and $\mathrm{Zn}$ can be modified in wheat through transgenic approaches.

Using knowledge from model species, it is possible now to identify more rapidly and with higher confidence candidate genes that might play a role in Fe and $\mathrm{Zn}$ transport. Access to relatively complete genomic sequence for polyploid wheat will allow more comprehensive phylogenetic studies for putative wheat homologs of large gene families. For example we have used the sequences of the rice natural resistance-associated macrophage proteins (NRAMPs) to identify wheat homologs (Table 1). Wheat candidate genes with putative $\mathrm{Fe}$ and $\mathrm{Zn}$ transporter function inferred from phylogeny, can be taken forward and characterized in yeast mutants, with a view eventually to expressing these in transgenic wheat plants to increase vacuolar export and ultimately nutrient content in the grain.

Work in rice has shown that multiplexing genes can further increase gains and this strategy could also be suitable for wheat. An analogous approach which would act to regulate several steps of the Fe and $\mathrm{Zn}$ uptake pathways would be to engineer transcriptional regulators to enhance movement and uptake into grains. For example the $N A M-B 1$ transcription factor provides an entry point to increase $\mathrm{Fe}, \mathrm{Zn}$, and protein content: with greater understanding of its targets, and which transport steps are key control points, we could engineer expression patterns, downstream targets, or binding specificities to improve nutrient content in the grain. The lack of genomic resources in wheat prompted initial studies on NAM-B1 to focus on rice, but these attempts failed since the orthologous rice $N A M$ gene affects anther dehiscence rather than mineral remobilisation (Distelfeld et al., 2012). The advent of new technologies and genomic resources now allow these questions to be addressed directly in wheat. In addition to RNA-seq (Cantu etal., 2011), we have developed transgenic lines with epitope-tagged NAM proteins to perform chromatin immunoprecipitation followed by sequencing (ChIP-seq) to identify direct targets of NAM (Borrill and Uauy, unpublished data). The availability of gene models and genomic sequence (including promoter regions) now makes this a feasible undertaking in wheat. 


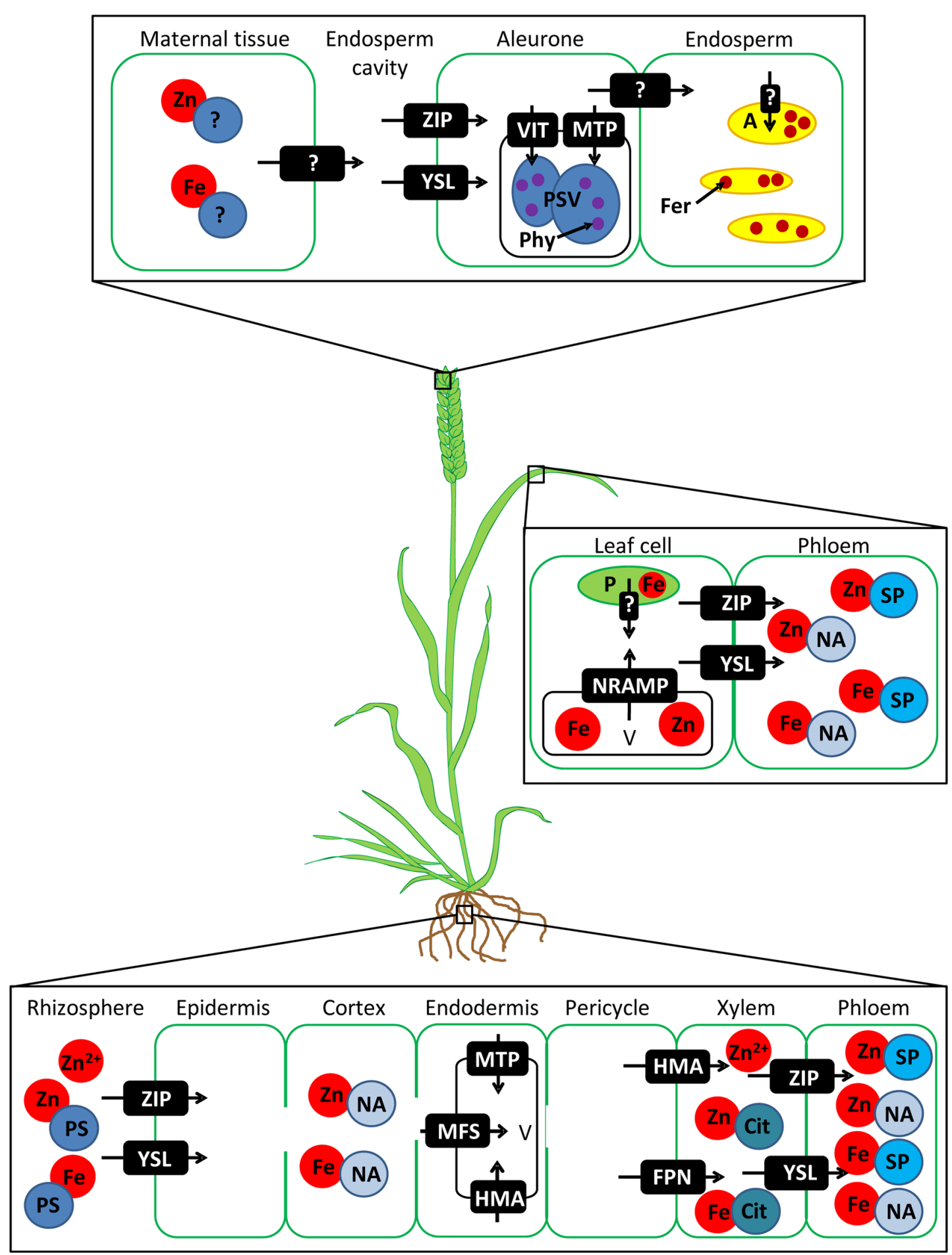

FIGURE 1 | Simplified proposed pathway for Fe and $\mathrm{Zn}$ uptake and translocation to the grain in wheat. Putative classes of transport proteins are shown in white text and are based on evidence from other species. Question marks show unidentified transporters. Free $\mathrm{Zn}^{2+}$ and phytosiderophore (PS) -bound Fe and $\mathrm{Zn}$ are absorbed from the soil into root epidermal cells. Fe and $\mathrm{Zn}$ move via the apoplast and symplast to the pericycle, but may be sequestered en-route in vacuoles. Fe and $\mathrm{Zn}$ are loaded into the xylem and transferred into the phloem in the root, basal shoot or leaf tissues (not shown). Fe and $\mathrm{Zn}$ are remobilised from leaf cell plastids $(P)$ and vacuoles $(V)$ and loaded into the phloem for transport to the ear. Fe and $\mathrm{Zn}$ are exported from the maternal tissue into the endosperm cavity. After uptake into the aleurone layer most $\mathrm{Fe}$ and $\mathrm{Zn}$ are sequestered in protein storage vacuoles (PSVs) bound to phytate (Phy). A small proportion of Fe and $\mathrm{Zn}$ may enter the endosperm and be stored bound to ferritin (Fer) in amyloplasts (A). ZIP = ZRT-, IRT-like protein, YSL = yellow stripe like transporter, MFS = major facilitator superfamily transporter, MTP = metal tolerance protein, $\mathrm{HMA}=$ heavy metal ATPase, FPN = ferroportin, NRAMP = natural resistance-associated macrophage protein, $\mathrm{VIT}=$ vacuolar iron transporter, $\mathrm{NA}=$ nicotianamine, $\mathrm{Cit}=$ citrate, $\mathrm{SP}=$ small proteins . 


\section{CHALLENGES IN TRANSFERRING KNOWLEDGE TO WHEAT}

As illustrated by NAM in rice and wheat it is important to note that the precise mechanisms of transport and its regulation differ between species even within monocots, so not all knowledge can be directly translated. It has been proposed that $\mathrm{Zn}$ transport to the grain in wheat is constrained by two major bottlenecks; the root-shoot barrier and grain filling (Palmgren et al., 2008). However in rice these bottlenecks are reduced (Stomph et al., 2009) as shown by the storage of excess $\mathrm{Zn}$ in shoots as well as roots (Jiang et al., 2008), and the ability of rice to load $\mathrm{Zn}$ from the xylem into the grain without transfer to the phloem (Zee, 1971), which constitutes a limiting step in wheat. Fe transport in rice and other monocots also differs, for example rice uses both secretion of PSs and direct uptake of $\mathrm{Fe}$ from the soil (Bughio et al., 2002; Inoue et al., 2009; Nozoye et al., 2011), whereas barley and maize only absorb Fe via PSs (Römheld and Marschner, 1986; Zaharieva and Römheld, 2000; Murata et al., 2006; Walker and Connolly, 2008). These challenges are compounded by the fact that several fundamental questions remain unanswered even in model species. The specificity of many transporters is not fully characterized and the control of flux through pathways requires further investigation. Additionally, the relative contribution of sink/source strength and the possible effects of manipulating individual metals on total grain metal composition are not well understood.

\section{CONCLUSIONS AND FUTURE DIRECTIONS}

Our ability to carry out basic research in wheat will be extremely important to build upon and move beyond research in model species. This will be greatly advanced by recent developments in genomic resources, mutant catalogs and transgenic methods. Once genes to improve nutrient content have been identified, they will need to be transferred into agriculturally relevant wheat varieties and assessed for agronomical traits such as yield and disease resistance which are the main drivers for adoption of novel varieties by farmers.

Changes to agricultural conditions in the future will also impact upon the deployment of biofortified wheat varieties. Rising atmospheric carbon dioxide $\left(\mathrm{CO}_{2}\right)$ concentrations may lead to reduced

Table 1 | New genomic resources enable identification of NRAMP homologs in wheat.

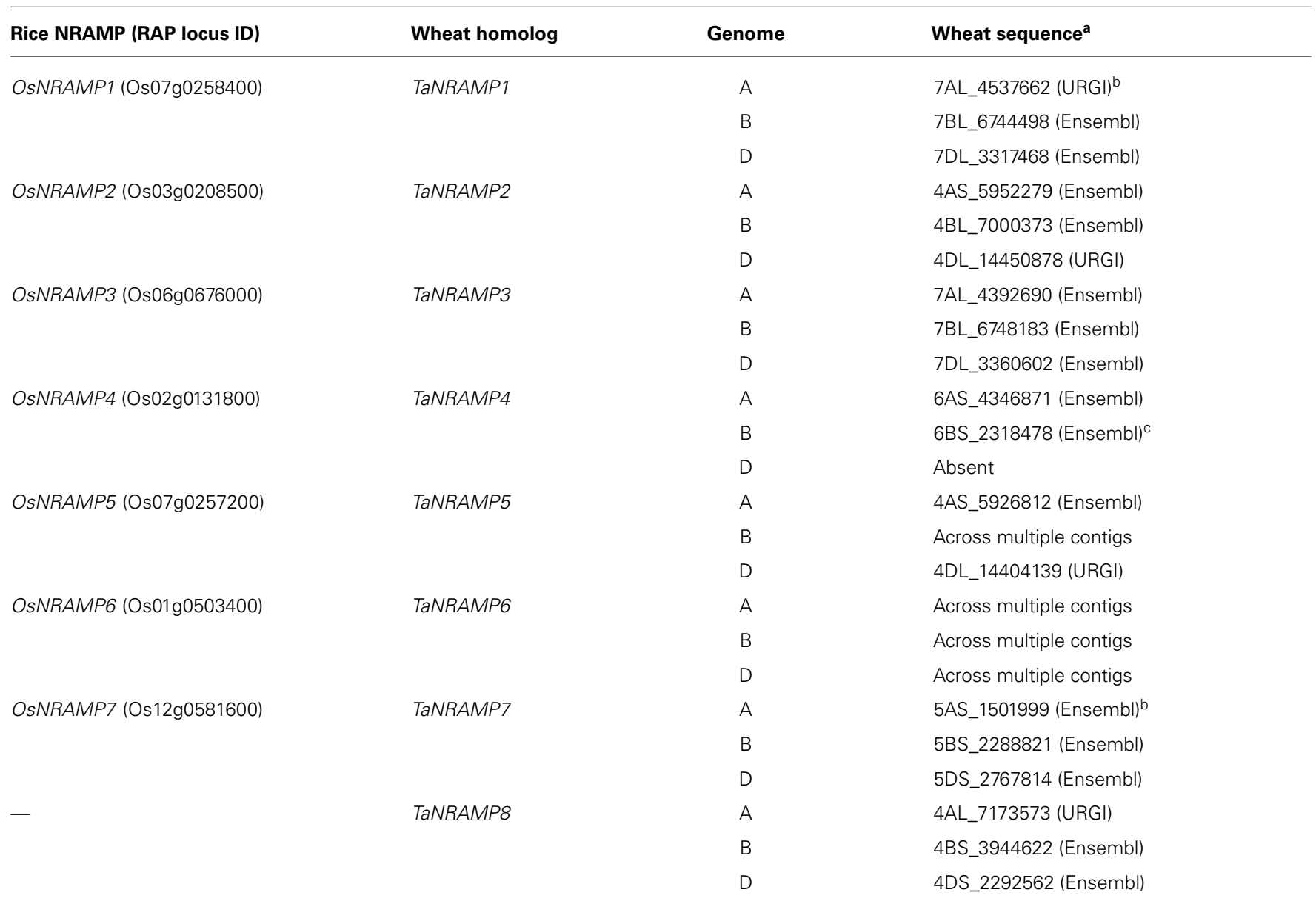

aInternational wheat genome sequencing consortium chromosome-arm survey sequences are available at EnsemblPlants (Ensembl; http://plants.ensembl.org/index.html) and at Unité de Recherche Génomique Info (URGl; http://www.wheatgenome.org/Tools-and-Resources)

b partial sequence

${ }^{\mathrm{c}}$ premature termination codon 
grain micronutrient content, especially $\mathrm{Fe}$, as has been shown by free air $\mathrm{CO}_{2}$ enrichment studies (Hogy et al., 2009; Fernando et al., 2012). Additionally lower levels of fertilizer may be used in the future due to budgetary and legal constraints. This may present a challenge to improve $\mathrm{Fe}$ and $\mathrm{Zn}$ grain concentrations because lower application of nitrogen fertilizer correlates to lower Fe and Zn grain concentrations (Cakmak et al., 2010). In addition, the drive for higher yields is usually accompanied by a dilution effect of minerals due to the additional grain starch accumulation. This scenario suggests that scientists and breeders will need to work ever more closely to achieve not just maintenance, but the required increased grain $\mathrm{Fe}$ and $\mathrm{Zn}$ contents.

Despite these challenges we believe that wheat researchers now have access to the tools and resources required to make significant improvements to Fe and $\mathrm{Zn}$ content in wheat grain and to bring these improved varieties to the field. These new varieties could make an important contribution to improving the health of millions of people worldwide to avoid Fe and $\mathrm{Zn}$ malnutrition which still affects over $25 \%$ of the global population.

\section{AUTHOR CONTRIBUTIONS}

Philippa Borrill and Cristobal Uauy wrote the manuscript; James M. Connorton, Janneke Balk, Anthony J. Miller, Dale Sanders contributed corrections and suggestions; Philippa Borrill, James M. Connorton, Cristobal Uauy analyzed the wheat genome sequence data for Table 1. Philippa Borrill, Janneke Balk, Anthony J. Miller, Dale Sanders, Cristobal Uauy conceived the perspective. All authors read and approved the final manuscript.

\section{ACKNOWLEDGMENTS}

This project was supported by grants BB/J004588/1 and BB/J004561/1 from the Biotechnology and Biological Sciences Research Council (BBSRC), grant 6242 from the HarvestPlus Challenge Program and the John Innes Foundation.

\section{REFERENCES}

Allen, A. M., Barker, G. L. A., Wilkinson, P., Burridge, A., Winfield, M., Coghill, J., et al. (2013). Discovery and development of exome-based, co-dominant single nucleotide polymorphism markers in hexaploid wheat (Triticum aestivum L.). Plant Biotechnol. J. 11, 279-295. doi: 10.1111/pbi.12009

Balmer, Y., Vensel, W. H., Dupont, F. M., Buchanan, B. B., and Hurkman, W. J. (2006). Proteome of amyloplasts isolated from developing wheat endosperm presents evidence of broad metabolic capability. J. Exp. Bot. 57, 1591-1602. doi: 10.1093/jxb/erj156

Borg, S., Brinch-Pedersen, H., Tauris, B., and Holm, P. (2009). Iron transport, deposition and bioavailability in the wheat and barley grain. Plant Soil 325, 15-24. doi: 10.1007/s11104-009-0046-6

Borg, S., Brinch-Pedersen, H., Tauris, B., Madsen, L. H., Darbani, B., Noeparvar, S., et al. (2012). Wheat ferritins: improving the iron content of the wheat grain. J. Cereal Sci. 56, 204-213. doi: 10.1016/j.jcs.2012.03.005

Brenchley, R., Spannagl, M., Pfeifer, M., Barker, G. L. A., D’Amore, R., Allen, A. M., et al. (2012). Analysis of the bread wheat genome using whole-genome shotgun sequencing. Nature 491, 705-710. doi: 10.1038/nature11650

Bughio, N., Yamaguchi, H., Nishizawa, N. K., Nakanishi, H., and Mori, S. (2002). Cloning an iron-regulated metal transporter from rice. J. Exp. Bot. 53, 1677-1682. doi: $10.1093 /$ jxb/erf004

Cakmak, I., Ozkan, H., Braun, H. J., Welch, R. M., and Romheld, V. (2000). Zinc and iron concentrations in seeds of wild, primitive, and modern wheats. Food Nutr. Bull. 21, 401-403.

Cakmak, I., Pfeiffer, W. H., and Mcclafferty, B. (2010). Biofortification of durum wheat with zinc and iron. Cereal Chem. 87, 10-20. doi: 10.1094/CCHEM-87-10010
Cantu, D., Pearce, S. P., Distelfeld, A., Christiansen, M. W., Uauy, C., Akhunov, E., et al. (2011). Effect of the down-regulation of the high Grain Protein Content (GPC) genes on the wheat transcriptome during monocarpic senescence. BMC Genomics 12:492. doi: 10.1186/1471-2164-12-492

Conte, S. S., and Walker, E. L. (2011). Transporters contributing to iron trafficking in plants. Mol. Plant 4, 464-476. doi: 10.1093/mp/ssr015

Curie, C., Cassin, G., Couch, D., Divol, F., Higuchi, K., Jean, M., et al. (2009). Metal movement within the plant: contribution of nicotianamine and yellow stripe 1-like transporters. Ann. Bot. Lond. 103, 1-11. doi: 10.1093/aob/mcn207

Deinlein, U., Weber, M., Schmidt, H., Rensch, S., Trampczynska, A., Hansen, T. H., et al. (2012). Elevated nicotianamine levels in Arabidopsis halleri roots play a key role in zinc hyperaccumulation. Plant Cell 24, 708-723. doi: 10.1105/tpc. 111.095000

Distelfeld, A., Cakmak, I., Peleg, Z., Ozturk, L., Yazici, A. M., Budak, H., et al. (2007). Multiple QTL-effects of wheat Gpc-B1 locus on grain protein and micronutrient concentrations. Physiol. Plant 129, 635-643. doi: 10.1111/j.1399-3054.2006.00841.x

Distelfeld, A., Pearce, S., Avni, R., Scherer, B., Uauy, C., Piston, F., et al. (2012). Divergent functions of orthologous NAC transcription factors in wheat and rice. Plant Mol. Biol. 78, 515-524. doi: 10.1007/s11103-012-9881-6

Duan, J., Xia, C., Zhao, G., Jia, J., and Kong, X. (2012). Optimizing de novo common wheat transcriptome assembly using short-read RNA-Seq data. BMC Genomics 13:392. doi: 10.1186/1471-2164-13-392

Fernando, N., Panozzo, J., Tausz, M., Norton, R., Fitzgerald, G., and Seneweera, S. (2012). Rising atmospheric CO2 concentration affects mineral nutrient and protein concentration of wheat grain. Food Chem. 133, 1307-1311. doi: 10.1016/j.foodchem.2012.01.105

Gomez-Galera, S., Rojas, E., Sudhakar, D., Zhu, C. F., Pelacho, A. M., Capell, T., et al. (2010). Critical evaluation of strategies for mineral fortification of staple food crops. Transgenic Res. 19, 165-180. doi: 10.1007/s11248-009-9311-y

Harwood, W. A. (2012). Advances and remaining challenges in the transformation of barley and wheat. J. Exp. Bot. 63, 1791-1798. doi: 10.1093/jxb/err380

Haydon, M. J., Kawachi, M., Wirtz, M., Hillmer, S., Hell, R., and Krämer, U. (2012). Vacuolar nicotianamine has critical and distinct roles under iron deficiency and for zinc sequestration in Arabidopsis. Plant Cell 24, 724-737. doi: 10.1105/tpc.111.095042

Hogy, P., Wieser, H., Kohler, P., Schwadorf, K., Breuer, J., Franzaring, J., et al. (2009). Effects of elevated CO2 on grain yield and quality of wheat: results from a 3-year free-air CO2 enrichment experiment. Plant Biol. 11, 60-69. doi: 10.1111/j.1438-8677.2009.00230.x

Holm, P. B., Kristiansen, K. N., and Pedersen, H. B. (2002). Transgenic approaches in commonly consumed cereals to improve iron and zinc content and bioavailability. J. Nutr. 132, 514S-516S.

Hurrell, R., Ranum, P., de Pee, S., Biebinger, R., Hulthen, L., Johnson, Q., et al. (2010). Revised recommendations for iron fortification of wheat flour and an evaluation of the expected impact of current national wheat flour fortification programs. Food Nutr. Bull. 31, S7-S21.

Inoue, H., Kobayashi, T., Nozoye, T., Takahashi, M., Kakei, Y., Suzuki, K., et al. (2009). Rice OsYSL15 is an iron-regulated iron(III)-deoxymugineic acid transporter expressed in the roots and is essential for iron uptake in early growth of the seedlings. J. Biol. Chem. 284, 3470-3479. doi: 10.1074/jbc.M806 042200

Jia, J. Z., Zhao, S. C., Kong, X. Y., Li, Y. R., Zhao, G. Y., He, W. M., et al. (2013). Aegilops tauschii draft genome sequence reveals a gene repertoire for wheat adaptation. Nature 496, 91-95. doi: 10.1038/nature 12028

Jiang, W., Struik, P. C., Van Keulen, H., Zhao, M., Jin, L. N., and Stomph, T. J. (2008). Does increased zinc uptake enhance grain zinc mass concentration in rice? Ann. Appl. Biol. 153, 135-147. doi: 10.1111/j.1744-7348.2008.00243.x

Kobayashi, T., and Nishizawa, N. K. (2012). Iron uptake, translocation, and regulation in higher plants. Annu. Rev. Plant Biol. 63, 131-152. doi: 10.1146/annurev-arplant-042811-105522

Krasileva, K., Buffalo, V., Bailey, P., Pearce, S., Ayling, S., Tabbita, F., et al. (2013). Separating homeologs by phasing in the tetraploid wheat transcriptome. Genome Biol. 14:R66. doi: 10.1186/gb-2013-14-6-r66

Kumar, J., Jaiswal, V., Kumar, A., Kumar, N., Mir, R. R., Kumar, S., et al. (2011). Introgression of a major gene for high grain protein content in some Indian bread wheat cultivars. Field Crops Res. 123, 226-233. doi: 10.1016/j.fcr.2011. 05.013 
Lee, S., Jeon, J. S., and An, G. (2012). Iron homeostasis and fortification in rice. J. Plant Biol. 55, 261-267. doi: 10.1007/s12374-011-0386-7

Lee, S., Jeon, U. S., Lee, S. J., Kim, Y.-K., Persson, D. P., Husted, S., et al. (2009). Iron fortification of rice seeds through activation of the nicotianamine synthase gene. Proc. Natl. Acad. Sci. U.S.A. 106, 22014-22019. doi: 10.1073/pnas.09109 50106

Li, J. R., Ye, X. G., An, B. Y., Du, L. P., and Xu, H. J. (2012). Genetic transformation of wheat: current status and future prospects. Plant Biotechnol. Rep. 6, 183-193. doi: 10.1007/s11816-011-0213-0

Ling, H. Q., Zhao, S. C., Liu, D. C., Wang, J. Y., Sun, H., Zhang, C., et al. (2013). Draft genome of the wheat A-genome progenitor Triticum urartu. Nature 496, 87-90. doi: 10.1038/nature11997

Lu, L., Tian, S., Zhang, J., Yang, X., Labavitch, J. M., Webb, S. M., et al. (2013). Efficient xylem transport and phloem remobilization of $\mathrm{Zn}$ in the hyperaccumulator plant species Sedum alfredii. New Phytol. 198, 721-731. doi: 10.1111/nph.12168

Monasterio, I., and Graham, R. D. (2000). Breeding for trace minerals in wheat. Food Nutr. Bull. 21, 392-396.

Morel, M., Crouzet, J., Gravot, A., Auroy, P., Leonhardt, N., Vavasseur, A., et al. (2009). AtHMA3, a P1B-ATPase allowing $\mathrm{Cd} / \mathrm{Zn} / \mathrm{Co} / \mathrm{Pb}$ vacuolar storage in Arabidopsis. Plant Physiol. 149, 894-904. doi: 10.1104/pp.108.130294

Murata, Y., Ma, J. F., Yamaji, N., Ueno, D., Nomoto, K., and Iwashita, T. (2006). A specific transporter for iron(III)-phytosiderophore in barley roots. Plant J. 46, 563-572. doi: 10.1111/j.1365-313X.2006.02714.x

Murray, C. J. L., and Lopez, A. D. (2013). Measuring the global burden of disease. N. Engl. J. Med. 369, 448-457. doi: 10.1056/NEJMra1201534

Nozoye, T., Nagasaka, S., Kobayashi, T., Takahashi, M., Sato, Y., Sato, Y., et al (2011). Phytosiderophore efflux transporters are crucial for iron acquisition in graminaceous plants. J. Biol. Chem. 286,5446-5454. doi: 10.1074/jbc.M110. 180026

Palmgren, M. G., Clemens, S., Williams, L. E., Kraemer, U., Borg, S., Schjorring, J. K., et al. (2008). Zinc biofortification of cereals: problems and solutions. Trends Plant Sci. 13, 464-473. doi: 10.1016/j.tplants.2008.06.005

Paux, E., Sourdille, P., Salse, J., Saintenac, C., Choulet, F., Leroy, P., et al. (2008). A physical map of the 1-Gigabase bread wheat chromosome 3B. Science 322, 101-104. doi: 10.1126/science.1161847

Randhawa, H. S., Asif, M., Pozniak, C., Clarke, J. M., Graf, R. J., Fox, S. L., et al (2013). Application of molecular markers to wheat breeding in Canada. Plant Breed. 132, 458-471. doi: 10.1111/pbr.12057

Regvar, M., Eichert, D., Kaulich, B., Gianoncelli, A., Pongrac, P., Vogel-Mikuš, K., et al. (2011). New insights into globoids of protein storage vacuoles in wheat aleurone using synchrotron soft X-ray microscopy. J. Exp. Bot. 62, 3929-3939. doi: 10.1093/jxb/err090

Rellán-Álvarez, R., Giner-Martínez-Sierra, J., Orduna, J., Orera, I., RodríguezCastrillón, J. Á., García-Alonso, J. I., et al. (2010). Identification of a tri-iron(III) tri-citrate complex in the xylem sap of iron-deficient tomato resupplied with iron: new insights into plant iron long-distance transport. Plant Cell Physiol. 51, 91-102. doi: 10.1093/pcp/pcp170

Römheld, V., and Marschner H. (1986). Evidence for a specific uptake system for iron phytosiderophores in roots of grasses. Plant Physiol. 80, 175-180. doi: 10.1104/pp.80.1.175

Safar, J., Bartos, J., Janda, J., Bellec, A., Kubalakova, M., Valarik, M., et al. (2004). Dissecting large and complex genomes: flow sorting and BAC cloning of individual chromosomes from bread wheat. Plant J. 39, 960-968. doi: 10.1111/j.1365-313X.2004.02179.x

Saintenac, C., Jiang, D., and Akhunov, E. (2011). Targeted analysis of nucleotide and copy number variation by exon capture in allotetraploid wheat genome. Genome Biol. 12, R88. doi: 10.1186/gb-2011-12-9-r88

Schroeder, J. I., Delhaize, E., Frommer, W. B., Guerinot, M. L., Harrison, M. J., Herrera-Estrella, L., et al. (2013). Using membrane transporters to improve crops for sustainable food production. Nature 497, 60-66. doi: 10.1038/nature 11909

Sestili, F., Botticella, E., Bedo, Z., Phillips, A., and Lafiandra, D. (2010). Production of novel allelic variation for genes involved in starch biosynthesis through mutagenesis. Mol. Breed. 25, 145-154. doi: 10.1007/s11032-00 9-9314-7

Sperotto, R. A., Ricachenevsky, F. K., Waldow, V. D., and Fett, J. P. (2012). Iron biofortification in rice: it's a long way to the top. Plant Sci. 190, 24-39. doi: 10.1016/j.plantsci.2012.03.004
Stomph, T. J., Wen, J., and Struik, P. C. (2009). Zinc biofortification of cereals: rice differs from wheat and barley. Trends Plant Sci. 14, 123-124. doi: 10.1016/j.tplants.2009.01.001

Sui, X., Zhao, Y., Wang, S., Duan, X., Xu, L., Liang, R., et al. (2012). Improvement Fe content of wheat (Triticum aestivum) grain by soybean ferritin expression cassette without vector backbone sequence. J. Agric. Biotechnol. 20, 766-773.

Tabbita, F., Lewis, S., Vouilloz, J. P., Ortega, M. A., Kade, M., Abbate, P. E., et al. (2013). Effects of the Gpc-B1 locus on high grain protein content introgressed into Argentinean wheat germplasm. Plant Breed. 132, 48-52. doi: 10.1111/pbr. 12011

Tauris, B., Borg, S., Gregersen, P. L., and Holm, P. B. (2009). A roadmap for zinc trafficking in the developing barley grain based on laser capture microdissection and gene expression profiling. J. Exp. Bot. 60, 1333-1347. doi: 10.1093/jxb/e rp023

Trick, M., Adamski, N., Mugford, S., Jiang, C.-C., Febrer, M., and Uauy, C. (2012). Combining SNP discovery from next-generation sequencing data with bulked segregant analysis (BSA) to fine-map genes in polyploid wheat. BMC Plant Biol. 12:14. doi: 10.1186/1471-2229-12-14

Uauy, C., Distelfeld, A., Fahima, T., Blechl, A., and Dubcovsky, J. (2006). A NAC gene regulating senescence improves grain protein, zinc, and iron content in wheat. Science 314, 1298-1301. doi: 10.1126/science.1133649

Uauy, C., Paraiso, F., Colasuonno, P., Tran, R. K., Tsai, H., Berardi, S., et al. (2009). A modified TILLING approach to detect induced mutations in tetraploid and hexaploid wheat. BMC Plant Biol. 9:115. doi: 10.1186/1471-22299-115

Walker, E. L., and Connolly, E. L. (2008). Time to pump iron: iron-deficiencysignaling mechanisms of higher plants. Curr. Opin. Plant Biol. 11, 530-535. doi: 10.1016/j.pbi.2008.06.013

Wang, M., Gruissem, W., and Bhullar, N. K. (2013). Nicotianamine synthase overexpression positively modulates iron homeostasis-related genes in high iron rice. Front. Plant Sci. 4:156. doi: 10.3389/fpls.2013.00156

Waters, B. M., and Sankaran, R. P. (2011). Moving micronutrients from the soil to the seeds: Genes and physiological processes from a biofortification perspective. Plant Sci. 180, 562-574. doi: 10.1016/j.plantsci.2010.12.003

Welch, R. M., and Graham, R. D. (2004). Breeding for micronutrients in staple food crops from a human nutrition perspective. J. Exp. Bot. 55, 353-364. doi: 10.1093/jxb/erh064

Wessells, K. R., and Brown, K. H. (2012). Estimating the global prevalence of zinc deficiency: results based on zinc availability in national food supplies and the prevalence of stunting. PLoS ONE 7:e50568. doi: 10.1371/journal.pone.00 50568

White, P. J., and Broadley, M. R. (2009). Biofortification of crops with seven mineral elements often lacking in human diets - iron, zinc, copper, calcium, magnesium, selenium and iodine. New Phytol. 182, 49-84. doi: 10.1111/j.14698137.2008.02738.x

White, P. J., and Broadley, M. R. (2011). Physiological limits to zinc biofortification of edible crops. Front. Plant Sci. 2:80. doi: 10.3389/fpls.2011.00080

WHO. (2008). Worldwide Prevalence of Anaemia 1993-2005: WHO Global Database on Anaemia, eds B. de Benoist, E. McLean, I. Egli, and M. Cogswell (Geneva: World Health Organization Press).

WHO. (2009). Global Health Risks. Mortality and Burden of Disease Attributable to Selected Major Risks. Available at: http://www.who.int/healthinfo/global_burden_ disease/GlobalHealthRisks_report_annex.pdf (accessed October 30, 2013).

Wilkinson, P., Winfield, M., Barker, G., Allen, A., Burridge, A., Coghill, J., etal. (2012). CerealsDB 2.0: an integrated resource for plant breeders and scientists. BMC Bioinformatics 13:219. doi: 10.1186/1471-210513-219

Winfield, M. O., Wilkinson, P. A., Allen, A. M., Barker, G. L. A., Coghill, J. A., Burridge, A., etal. (2012). Targeted re-sequencing of the allohexaploid wheat exome. Plant Biotechnol. J. 10, 733-742. doi: 10.1111/j.1467-7652.2012. 00713.x

Wirth, J., Poletti, S., Aeschlimann, B., Yakandawala, N., Drosse, B., Osorio, S., et al. (2009). Rice endosperm iron biofortification by targeted and synergistic action of nicotianamine synthase and ferritin. Plant Biotechnol. J. 7, 631-644. doi: 10.1111/j.1467-7652.2009.00430.x

Zaharieva, T., and Römheld, V. (2000). Specific Fe uptake system in strategy I plants inducible under Fe deficiency. J. Plant Nutr. 23, 1733-1744. doi: 10.1080/01904160009382137 
Zee, S. Y., and O’Brien, T. P. (1970). A special type of tracheary element associated with xylem-discontinuity in floral axis of wheat. Aust. J. Biol. Sci. 23, 783-791. doi: 10.1071/BI9700783

Zee, S. Y. (1971). Vascular tissue and transfer cell distribution in the rice spikelet. Aust. J. Biol. Sci. 25, 411-414.

Conflict of Interest Statement: The authors declare that the research was conducted in the absence of any commercial or financial relationships that could be construed as a potential conflict of interest.

Received: 30 October 2013; accepted: 04 February 2014; published online: 21 February 2014
Citation: Borrill P, Connorton JM, Balk J, Miller AJ, Sanders D and Uauy C (2014) Biofortification of wheat grain with iron and zinc: integrating novel genomic resources and knowledge from model crops. Front. Plant Sci. 5:53. doi: 10.3389/fpls.2014.00053

This article was submitted to Plant Nutrition, a section of the journal Frontiers in Plant Science.

Copyright (c) 2014 Borrill, Connorton, Balk, Miller, Sanders and Uauy. This is an open-access article distributed under the terms of the Creative Commons Attribution License (CC BY). The use, distribution or reproduction in other forums is permitted, provided the original author(s) or licensor are credited and that the original publication in this journal is cited, in accordance with accepted academic practice. No use, distribution or reproduction is permitted which does not comply with these terms. 